\title{
LÍMITES A LA LIBERTAD DE EXPRESIÓN DE LOS POLÍTICOS Y ABUSO DE DERECHO. LOS CASOS FÉRET C. BÉLGICA Y PERINÇEK C. SUIZA
}

MARÍA J. ROCA 


\section{SUMARIO}

1. INTRODUCCIÓN. 2. EXPOSICIÓN SUMARIA DE AMBAS SENTENCIAS. 2.1. Féret c. Bélgica. 2.1.1. Resumen de los hechos. 2.1.2. Resumen de la decisión. 2.1.3. Consideraciones finales. 2.2. Perinçek c. Suiza. 2.2.1. Resumen de los hechos. 2.2.2. Resumen de la decisión. 2.2.3. Consideraciones finales. 3. CRITERIOS INTERPRETATIVOS DE LOS LÍMITES A LA LIBERTAD DE EXPRESIÓN DE LOS POLÍTICOS. 3.1. Libertad de expresión de la clase política. 3.2. Criterios interpretativos de algunos conceptos jurídicos indeterminados de Derecho convencional. 3.3. Aplicación restrictiva del art. 17 del CEDH. 4. CONSIDERACIONES CONCLUSIVAS. 5. REFERENCIAS BIBLIOGRÁFICAS 
Fecha recepción: 14/05/2020

Fecha aceptación: 06/09/2020

\title{
LÍMITES A LA LIBERTAD DE EXPRESIÓN DE LOS POLÍTICOS Y ABUSO DE DERECHO. LOS CASOS FÉRET C. BÉLGICA Y PERINÇEK C. SUIZA
}

\author{
MARÍA J. ROCA*
}

\section{INTRODUCCIÓN}

La estrecha relación e interdependencia entre la libertad de expresión y la democracia es un aspecto pacífica y generalmente aceptado, siempre que se trata de este derecho, ya sea en decisiones judiciales ${ }^{1}$ o en estudios doctrinales ${ }^{2}$. Por otra parte, es igualmente estrecha la relación entre los partidos políticos y la democracia, pues difícilmente una democracia puede serlo realmente, si no es representativa; y, en la

* Catedrática de Derecho Constitucional (Universidad Complutense de Madrid). Dirección postal: Departamento de Derecho Constitucional. Facultad de Derecho Universidad Complutense, Plaza Menéndez Pelayo, 4, 28040 Madrid. Correo electrónico: mjroca@der.ucm.es

Este trabajo es la versión en castellano y actualizada de la ponencia pronunciada en el Seminario Humboldt sobre el derecho a la libertad de expresión celebrado en la sede del TEDH los días 26-27 de abril de 2019.

1 El Tribunal Constitucional Federal alemán ha acuñado la expresión demokratisch-funktionale Dimension der Meinungsfreibeit (dimensión democrático-funcional de la libertad de expresión).

2 Combalía Solís, Z. (2017). «Libertad de expresión y religión en Estados Unidos y en Europa: dos modos de entender la democracia», en: Revista General de Derecho Canónico y Derecho Eclesiástico del Estado, n. 45, pone de manifiesto que la concepción amaricana es más abierta y la europea más tuitiva. Bustos Gisbert, R. (2014). «Los derechos de libre comunicación en una sociedad democrática», en: García Roca J. / Santolaya, P. (coords.), La Europa de los derechos: El Convenio Europeo de Derechos Humanos $3^{a}$ ed., CEPC, Madrid, pp. 473-509, critica moderadamente los límites a la libertad de expresión en el contexto europeo, especialmente en algunos ámbitos. CATALÀ i BAS, A. H. (200I). « ¿Tolerancia frente a la intolerancia? El respeto a los valores y principios democráticos como límite a la libertad de expresión», en Cuadernos de Derecho Público, n. 14, especialmente las pp. 136 y ss. CATALÀ I BAs, A. H. (200I). Libertad de expresión e información. La jurisprudencia del TEDH y su recepción por el Tribunal Constitucional: hacia un derecho europeo de los derechos humanos, Ediciones Revista General de Derecho, Valencia, pp. 234 y ss. 
representación, desempeñan un papel, hoy por hoy insustituible, los partidos políticos.

En el presente trabajo, nos proponemos estudiar si en la jurisprudencia del TEDH los representantes políticos tienen solo y únicamente los límites generales que tiene el ejercicio de la libertad de expresión para cualquier otro ciudadano, o si, por el contrario, esos límites presentan alguna peculiaridad por ejercer al mismo tiempo que su libertad de expresión una representación política.

Para nuestro trabajo hemos elegido dos sentencias del TEDH que nos parecen muy significativas. En Féret c. Bélgica ${ }^{3}$, la libertad de expresión debe ceder frente a la protección de los derechos fundamentales de los miembros de un grupo especialmente vulnerable (los extranjeros); en cambio, en Perinçek c. Suiza, la libertad de expresión de un político prevalece frente a los derechos de los miembros de otro grupo (el pueblo armenio). En el ap. 2 exponemos someramente los hechos (ap. 2.1.1. y 2.1.2.) y un resumen de la fundamentación en Derecho de cada decisión (ap. 2.2.1. y 2.2.2.), para ponderar, en el ap. 3, los criterios interpretativos de los límites a la libertad de expresión de los políticos. En el ap. 4, se ofrecen unas consideraciones finales.

\section{EXPOSICIÓN SUMARIA DE AMBAS SENTENCIAS}

\subsection{Féret c. Bélgica}

El TEDH sostuvo, por 4 votos frente a 3, que no hubo violación del art. 10 (libertad de expresión) del CEDH en la condena impuesta por la jurisdicción belga al recurrente, que era el presidente del partido político «Frente Nacional», por publicidad incitando a la discriminación o al odio, en unos panfletos distribuidos por este partido durante la campaña. Como la solicitud preliminar en virtud del art. 10 fue rechazada, otros aspectos de la solicitud no se consideraron admisibles.

3 Esta sentencia ha sido mencionada por el TEDH, al menos en las siguientes decisiones posteriores: Perinçek c. Suiza, de 15 de octubre de 2015, Vejdeland y otros c. Suecia, de 5 de Septiembre de 2012, Rabbae c. Holanda, de 18 de Noviembre de 2016; Estado de Holanda c. Wilders, de 9 de Diciembre de 2016; Stern Taulats and Roura Capellera c. España, de 13 de Marzo de 2018; Stomakhin c. Rusia, de 9 de Mayo de 2018; Savva Terentyev c. Rusia, de 28 de Agosto de 2018; Kaboğlu c. Turquía, de 30 de Octubre de 2018. También ha sido citada por TS español (Sala de lo penal) en la Sentencia 79/2018, de 2 de Febrero de 2018. STS 397/2018 - ECLI: ES:TS:2018:397, y por TC español en la Sentencia 177/2015, de 22 de julio de 2015. ECLI:ES:TC:2015:177

4 Féret c. Belgique, 16 de julio de 2009. Versión oficial en francés. Un resumen en castellano, por Domènec Sibina Tomàs puede verse en: QDL. Cuadernos de Derecho Local, n. 22, febrero de 2010, pp. 192-196. Accesible en https://repositorio.gobiernolocal.es/xmlui/handle/10873/3 [último acceso 25-042020]. También accesible en la base de datos de Aranzadi. 


\subsubsection{Resumen de los hechos}

El Sr. Féret, nacional belga nacido en 1944 y residente en Bruselas, era el redactor jefe de las publicaciones del partido y miembro de la Cámara de representantes durante el tiempo en que sucedieron los hechos del caso sometido al TEDH. Su inmunidad parlamentaria fue suspendida a petición del fiscal cuando, en noviembre de 2002, se inició un proceso penal contra Féret como autor y jefe de la edición de los panfletos ofensivos.

Entre julio de 1999 y octubre de 2001, la distribución de los panfletos y posters por el Frente Nacional, condujo a quejas individuales y de asociaciones por incitar al odio, a la discriminación y a la violencia, presentadas en virtud de una ley, de 30 de julio de $1981^{5}$, que penaliza ciertos actos inspirados en el racismo y la xenofobia. El material se distribuía a través de internet en la página web del Sr. Féret y del Frente Nacional. El contenido de los folletos reflejaba textos como los siguientes ${ }^{6}$ : salvar a nuestro pueblo de los riesgos que supone el Islam conquistador; otorgar la prioridad de empleo a los belgas y a los europeos; aplicar el principio de preferencia nacional y europea, convertir los centros de refugiados políticos en centros de acogida para los belgas sin techo, interrumpir la política de pseudo integración social y reservala a los belgas y a los europeos realmente perseguidos por razones políticas, etc.

\subsubsection{Resumen de la decisión}

La libertad de expresión es un factor importante en una sociedad democrática, y, particularmente para una persona que ha sido elegida por el pueblo, representa al electorado y defiende sus intereses. El tribunal reiteró su importancia para los políticos cuando se expresan en público, ya que las posibilidades de llegar a un amplio número de destinatarios y la capacidad de influencia es mayor. Por lo tanto, en estos supuestos, aumenta también la necesidad de evitar comentarios que puedan fomentar la intolerancia. En un contexto electoral, los argumentos naturalmente se vuelven más contundentes, y por eso el impacto del discurso racista y xenófobo se magnificaría. En el presente caso, había una necesidad imperiosa de proteger los derechos de las minorías y la comunidad inmigrante. A juicio del TEDH, los tribunales belgas han actuado adecuadamente condenando al Sr. Féret.

El TEDH sostiene que «la incitación al odio no requiere necesariamente el llamamiento a tal o cual acto de violencia ni a otro acto delictivo. Los ataques que se cometen contra las personas al injuriar, ridiculizar o difamar a ciertas partes de la población y sus grupos específicos o la incitación a la discriminación, como en el caso

5 En los $§ 42-43$ de la Sentencia se reproducen los preceptos que se le aplicaron al Sr. Féret.

6 En los $§ 7-18$ de la Sentencia se recogen con detalle las expresiones por las que el Sr. Féret fue condenado.

(C) UNED. Revista de Derecho Politico

N. ${ }^{\circ} 109$, septiembre-diciembre 2020, págs. 345-370 
de autos, son suficientes para que las autoridades privilegien la lucha contra el discurso racista frente a una libertad de expresión irresponsable y que atenta contra la dignidad, incluso la seguridad de tales partes o grupos de la población. Los discursos políticos que incitan al odio basado en prejuicios religiosos, étnicos o culturales representan un peligro para la paz social y la estabilidad política en los Estados democráticos» ${ }^{7}$.

El TEDH examina si la condición de parlamentario del demandante puede considerarse o no circunstancia atenuante de su responsabilidad, y concluye que no ${ }^{8}$ : es de crucial importancia que los políticos, en sus discursos públicos, eviten difundir palabras susceptibles de fomentar la intolerancia9. Estima que los políticos deberían ser particularmente escrupulosos, en términos de defensa de la democracia y de sus principios, puesto que su objetivo último es la propia toma del poder. (...). El Tribunal considera que «la incitación a la exclusión de extranjeros constituye una lesión fundamental de los derechos de las personas y debería justificar, en consecuencia, la precaución especial de todos, incluidos los políticos» ${ }^{10}$.

«Si en un contexto electoral los partidos políticos han de gozar de una amplia libertad de expresión al objeto de tratar de convencer a sus electores, en el caso de un discurso racista o xenófobo, tal contexto contribuye a avivar el odio o la intolerancia ya que, por la fuerza de las cosas, la posición de los candidatos a las elecciones tiende a fortalecerse y los eslóganes y fórmulas estereotipadas tienden a imponerse sobre los argumentos razonables. El impacto de un discurso racista y xenófobo es entonces mayor y más dañino» ${ }^{11}$.

No niega el TEDH que los partidos políticos tienen derecho a defender públicamente sus opiniones, incluso si algunas de ellas ofenden, chocan o inquietan a una parte de la población y que pueden recomendar soluciones para los problemas relativos a la inmigración. Sin embargo, «deben evitar hacerlo promoviendo la discriminación racial y recurriendo a expresiones o actitudes vejatorias o humillantes, ya que tal comportamiento puede suscitar en el público reacciones incompatibles con un clima social sereno y podría minar la confianza en las instituciones democráticas» ${ }^{12}$.

$7 \S 73$.

8 Jongen, F.; Strowel, A. (2017) Droit des médias et de la communication. Presse, audiovisuel et internet. Droit européen et belge, Bruxelles, n. marginal 85.

9 El TEDH cita jurisprudencia anterior: Erbakan c. Turquía, de 6 de julio de 2006, $\$ 64$.

$10 \$ 75$, se indica además, que la condición de parlamentario del demandante, no debería ser considerada como circunstancia atenuante.

$11 \S 76$.

$12 \S 77$. 
La sentencia cuenta con las opiniones disidentes de tres magistrados ${ }^{13}$, para quienes «confirmar la represión penal del discurso político es contrario a la libertad de expresión». Destacan que la mayor parte de las frases enjuiciadas, han sido tomadas del programa del Frente Popular distribuido en la campaña electoral ${ }^{14}$, y el partido no ha sido prohibido. En opinión de los magistrados disidentes, las declaraciones del Sr. Féret no constituyen un llamamiento a la violencia contra una parte de la población, en cuyo caso las autoridades internas gozarían de un margen de apreciación más amplio.

\subsubsection{Consideraciones finales}

A nuestro parecer, los fundamentos de esta sentencia contienen las principales cuestiones que ha resuelto la jurisprudencia de Estrasburgo sobre la libertad de expresión de los políticos: si su libertad de expresión experimenta límites más o menos amplios de los que afectan a otro ciudadano, por el hecho de ejercer representación política $^{15}$; si se ha de tener en cuenta la circunstancia de que las manifestaciones hayan sido difundidas en campaña electoral, y, por último, la relación entre el contenido de las manifestaciones y el programa político de su partido. Intentaremos dar respuesta a estas cuestiones en el ap. 3. En todo caso, adelantamos que sería considerar de modo simplista esta decisión, si se atribuyese al TEDH una preferencia política. A mi pare-

13 Opinión disidente del Magistrado Andràs Sajó a la que se adhieren los Magistrados Vladimiro Zagrebelsky y Nona Tsotsoria.

14 Véase el $\S 9$ de la sentencia, donde se recogen los asertos contenidos en el programa electoral del partido «Frente Nacional». En el $\S 70$, el TEDH considera que la Corte de apelación belga, no fundamenta su decisión en el programa político de un partido, sino en los hechos que se recogen en los § 8-17 de la STEDH.

15 En jurisprudencia ( p. ej.: Sentencia Vgt Verein gegen Tierfabriken c. Suisse § 66) anterior se ha sostenido con claridad que la libertad de expresión «... est assortie d'exceptions qui appellent toutefois une interprétation étroite et le besoin de la restreindre doi se trouver établie de manière convaincante, particulièrement si la nature du discours est politique plutôt que commerciale» (va acompañada de excepciones que, sin embargo, requieren una interpretación restrictiva y la necesidad de restringirla debe establecerse de manera convincente, particularmente si la naturaleza del discurso es polític más que comercial ).

(C) UNED. Revista de Derecho Politico

N. ${ }^{\circ} 109$, septiembre-diciembre 2020, págs. 345-370 


\author{
cer, no es así, pues en los casos de Le Pen en Francia ${ }^{16}$, el Tribunal ${ }^{17}$ falló a favor del \\ político del partido conservador.
}

16 El día 22.10.2007 el TEDH adoptó dos decisiones confirmando a las adoptadas por la justicia francesa, protegiendo el honor del político francés Jean-Marie Le Pen. Estas decisiones juzgaban las opiniones publicadas en prensa y en un libro, en las que se calificaba a este político francés como el «jefe de una banda de asesinos».

El punto de partida de esta disputa legal fue la publicación de la novela «El proceso de Jean-Marie Le Pen» del autor Mathieu Lindon en 1998 por P.O.L. La novela trataba sobre un juicio por asesinato contra el personaje principal ficticio «Ronald Blistier», quien, como partidario del verdadero partido extremista de derecha «Front National», mata a un joven marroquí. El tema principal de la novela fue explicar la supuesta responsabilidad del líder del partido Le Pen por las acciones de sus partidarios. Entre otras cosas, Le Pen fue descrito en el libro como el jefe de una «pandilla de asesinos» y como un «vampiro» que se alimenta de la amargura de sus jóvenes seguidores, pero a veces también de su «sangre». Le Pen había defendido con éxito esta publicación con una demanda por difamación ante un tribunal correccional de París. Los jueces penales encontraron que en un total de cuatro pasajes de la novela hubo declaraciones difamatorias y perjudiciales con respecto a Le Pen, que debido a su intensidad ya no podían justificarse por el derecho a la libertad de expresión, y condenaron a los dos acusados (los autores Lindon y el director editorial Paul Otchakovsky-Laurens) en octubre de 1999 al pago de una multa, cuyo importe aproximado ascendía a 2,300 €, así como a una compensación conjunta por el importe aproximado de $3.800 €$. Esta decisión también fue confirmada en la corte de apelaciones.

En otro juicio, el entonces editor en jefe del diario francés «Liberation», Serge July, fue multado por la misma cantidad por difamar a Le Pen. Como resultado del veredicto de primera instancia contra Lindon y Otchakovsky-Laurens, el peródico había publicado una petición de un total de 97 escritores franceses contemporáneos que protestaban contra la decisión del tribunal. En la petición, los pasajes en disputa fueron nuevamente reproducidos textualmente y confirmados por los firmantes. Un recurso contra esta sentencia tampoco tuvo éxito.

Los tres acusados acudieron conjuntamente al TEDH por una violación de la libertad de expresión de conformidad con Art. $10 \mathrm{CEDH}$, cuya sentencia ha sido emitida. Los jueces de Estrasburgo concluyeron que si bien la condena de Lindon y Otchakovsky-Laurens era una restricción de la libertad de expresión, estaba justificada en el presente caso y se consideraba necesaria en una sociedad democrática para proteger los derechos de los demás, especialmente aquí proteger la reputación de una persona. Un político, especialmente si él, como Le Pen, toma posiciones extremas, tiene que soportar un nivel especial de crítica y declaraciones negativas sobre sí mismo como más tolerantes que alguien que es una persona sin relevancia pública. Sin embargo, también hubo límites que los jueces consideraron excedidos en el presente caso. El monto de la pena impuesta también fue moderado y, por lo tanto, apropiado. Con respecto a la sentencia del editor jefe de Liberation, los jueces declararon que el ejercicio del derecho a la libertad de expresión implica ciertos deberes y responsabilidades. En los medios, esto incluye la obligación de amparar las opiniones controvertidas en hechos veraces, especialmente cuando se trata de la reputación de un personaje público. En el caso de la condena de Serge July, la restricción de la libertad de expresión estaba justificada para proteger la reputación de la persona interesada, según la sentencia.

17 La Sentencia del TEDH, de 22.10.2007, en el caso Lindon, Otchakovsky-Laurens et July c. Francia (Az. 21279/02 y 36448/02) puede verse en inglés y en francés en: http://www.echr.coe.int. 


\subsection{Perinçek c. Suiza ${ }^{18}$}

\subsubsection{Resumen de los hechos}

En 2005, el Sr. Doğu Perinçek, presidente del Partido de los Trabajadores de Turquía, hizo tres declaraciones públicas en distintas ocasiones en Suiza sobre el genocidio armenio. En primer lugar, durante una conferencia de prensa en Lausana, dijo: «Permítanme decir a la opinión pública europea de Berna y Lausana: las acusaciones del 'genocidio armenio' son una mentira internacional (...) inventada por primera vez en 1915 por los imperialistas de Inglaterra, Francia y la Rusia zarista, que querían dividir el Imperio Otomano durante la Primera Guerra Mundial».

En segundo lugar, durante un evento público en Zürich, denunció implícitamente la existencia del genocidio al afirmar que «el problema kurdo y el problema armenio, por lo tanto, no eran un problema y, sobre todo, ni siquiera existían». Luego, en septiembre de 2005, durante un mitin del Partido de los Trabajadores de Turquía en Berna, Perinçek sostuvo que «incluso Lenin, Stalin y otros líderes de la revolución soviética que escribieron sobre la cuestión armenia, dijeron en sus informes que las autoridades turcas no habían llevado a cabo ningún genocidio del pueblo armenio».

Después de la segunda declaración, la Asociación Suiza-Armenia presentó una denuncia penal contra Perinçek. En marzo de 2007, el Tribunal de Policía de Distrito de Lausana lo declaró culpable de violar el artículo 261 bis $\$ 4$ del Código Penal, que impone prisión de hasta tres años o una multa contra «cualquier persona que denigre o discrimine públicamente a una persona o grupo de personas por su raza, origen étnico o religión de una manera que viole la dignidad humana, ya sea a través de palabras, material escrito, imágenes, gestos, actos de agresión u otros medios, o cualquier persona que por los mismos motivos niega, groseramente trivializa o busca justificar un genocidio u otros crímenes contra la humanidad». El tribunal condenó a Perinçek a pagar 100 francos suizos durante 90 días, una suma de 3.000 francos suizos, reemplazables por 30 días de prisión, y 1.000 francos suizos a la Asociación Suiza-Armenia por daños morales. En junio de 2007, la División de Casación Criminal del Cantón de Vaud desestimó la apelación de Perinçek, al considerar que había negado el genocidio armenio, reconocido como «hecho histórico probado» por el

18 Perinçek C. Suisse, la sentencia de la sala es de 17 diciembre 2013; la sentencia de la Gran Sala es de 15/10/2015. Un buen resumen en castellano, puede verse en BouAZZA AriÑo, O. (2014). «Notas de Jurisprudencia del Tribunal Europeo de Derechos Humanos», en: Revista de Administración Pública, n. 194, pp. 257 y ss. Para una visión desde el punto de vista armenio de esta sentencia, véase TuNCEL, T. K. (2015). «A look at the Perinçek v. Switzerland case: examination of a lawsuit to understand the current state of the Armenian-Turkish dispute and prospective developments», en: Review of Armenian Studies, n. 31, pp. 293-324. Accesible en Academia.edu/31442451/A_LOOK_AT_THE_ PERİNÇEK_V._SWITZERLAND_CASE_EXAMINATION_OF_A_LAWSUIT_TO_ UNDERSTAND_THE_CURRENT_STATE_OF_THE_ARMENIAN- $\bar{T}$ TURKISH_DISPUTE_AND_PROSPECTIVE_DEVELOPMENTS [último acceso 25-04-2020].

(C) UNED. Revista de Derecho Politico

N. ${ }^{\circ} 109$, septiembre-diciembre 2020, págs. 345-370 
Poder legislativo de Suiza. En diciembre de 2007, el Tribunal Federal de Suiza rechazó la apelación de esa sentencia.

En junio de 2008, Perinçek presentó una demanda ante el TEDH. Entre otros motivos, alegó que los tribunales suizos habían violado injustamente su derecho a la libertad de expresión garantizado en el art. 10 del CEDH al condenarlo por negar el genocidio armenio. La Cámara concluyó que las razones dadas por el tribunal nacional de Suiza eran insuficientes para justificar su condena. En particular, sostuvo que a la luz de todas las circunstancias, «la condena no equivalía a una 'necesidad social apremiante' ni era 'necesaria en una sociedad democrática', para proteger el honor y los sentimientos de los descendientes de las víctimas de las atrocidades que datan de vuelta a 1915 y años posteriores» ${ }^{19}$.

En marzo de 2014, el Gobierno suizo solicitó que el caso se remitiera a la Gran Sala. Ésta sostuvo que la condena penal de Perinçek constituía una forma de interferencia del Gobierno con su derecho a la libertad de expresión, aunque estaban previstas por la ley y fueron prescritas de conformidad con el objetivo legítimo de proteger la identidad y la dignidad de los armenios. Al ponderar el equilibrio entre el derecho a la libertad de expresión garantizado en el art. 10 y el derecho a la vida privada del art. 8 del CEDH, la Gran Sala concluyó que la interferencia del Gobierno suizo con el derecho de Perinçek a la libertad de expresión no era necesaria en una sociedad democrática y que, por tanto, el art. 10 había sido lesionado.

El Gobierno suizo sostuvo que el castigo estaba justificado a tenor del art. $16^{20}$ del CEDH. La Corte argumentó que el art. 16 había sido invocado una sola vez en el contexto de la libertad de expresión: el caso Piermont c. Francia ${ }^{21}$, en el que un ciudadano alemán es expulsado de Francia, a consecuencia de su discurso. El TEDH consideró que el art. 16 no era aplicable, porque se trataba de un ciudadano de otro Estado miembro; no era extranjero en el sentido del art. 16. El art. 16 debe interpretarse como susceptible solo de autorizar restricciones a las «actividades» que afectan directamente el proceso político del Estado parte, y no el derecho del extranjero a las libertades de opinión y expresión ${ }^{22}$.

19 The Swiss domestic courts «Did not show, in particular, that [his] conviction met a 'pressing social need' or that it was 'necessary in a democratic society' for the protection of the honour and feelings of the descendants of the victims of the atrocities dating back to 1915 and subsequent years.» $\S 129$ de la sentencia Perinçek v. Switzerland, Application n. 27510/08 (2013).

20 Art. 16: «Ninguna de las disposiciones de los arts. 10, 11 y 14 podrá ser interpretada en el sentido de prohibir a las Altas Partes Contratantes imponer restricciones a la actividad política de los extranjeros». Un comentario a este precepto puede verse en LASAGABASTER HerrarTe, I. (2015). «Restricciones a la actividad política de los extranjeros», en: LASAgabaster Herrarte, I., (dir.), Convenio Europeo de Derechos Humanos. Comentario sistemático, $3^{\text {a }}$ ed., Cizur Menor (Navarra), pp. 819-823.

21 Series A n. 314 (1995). Un comentario a esta sentencia puede verse en PARIENTE dE LA PradA, I. (1996). «Un Nuevo concepto de ciudadanía europea: Comentario a la Sentencia del Tribunal Europeo de Derechos Huamnos de 27 de abril de 1995 en el Asunto Piermont c. Francia», en: Revista Vasca de Adminsitración Pública, 44 (I), pp. 231-250.

$22 \S 121$. 
La segunda cuestión era si la condena penal de Perinçek constituía una injerencia justificada en virtud del art. 10 del CEDH. Según el Tribunal, para que una injerencia se considere justificada, «debe haber sido 'prescrita por ley', destinada a uno o más de los objetivos legítimos [art. 10.2], y 'necesaria en una sociedad democrática' para lograr ese objetivo u objetivos» ${ }^{23}$. Además, enfatizó que la expresión «prescrita por la ley» denota que las medidas restrictivas de los gobiernos deben formularse con «suficiente precisión para permitir que la persona interesada regule su conducta...» ${ }^{24}$ El Tribunal primero abordó la cuestión de si en el momento de expresar sus declaraciones, Perinçek sabía o debería haber sabido que eran susceptibles de hacerlo penalmente responsable. El gobierno sostuvo que el art. 261 bis $\S 4$ de su Código Penal tipifica como delito negar tanto el genocidio como los crímenes de lesa humanidad. El Tribunal tomó nota que el Sr. Perinçek admitió ante las autoridades judiciales, que sabía que el Consejo Nacional Suizo había reconocido los acontecimientos de 1915 como un genocidio contra los armenios. A la luz de este hecho, sostuvo que su condena y castigo eran «suficientemente previsibles y, por lo tanto, 'prescritos por la ley' en el sentido del art. $10 \S 2$ de la Convención» ${ }^{25}$.

La última cuestión era si esa interferencia era necesaria en una sociedad democrática. De conformidad con su jurisprudencia, la Corte señaló que el adjetivo «necesario», en virtud del art. 10 implica «la existencia de una necesidad social apremiante». Pero los Estados parte en la Convención disfrutan de un margen de apreciación ${ }^{26}$ al evaluar si existe tal necesidad. En Aksu v. Turquía ${ }^{27}$, la Corte sostuvo que «los estereotipos negativos de un grupo étnico eran capaces, al alcanzar cierto nivel, de tener un impacto en el sentido de identidad del grupo y en los sentimientos de autoestima y confianza de sus miembros», y, por lo tanto, este estereotipo negativo estaba dentro del significado del art. 8 del CEDH sobre el derecho a la vida privada. Debido a que la identidad del pueblo armenio se percibía como un grupo que sufrió atrocidades durante los eventos de 1915, la Corte primero procedió a realizar un juicio de ponderación para lograr el equilibrio entre el derecho a la libertad de expresión y el derecho a la vida privada.

El Tribunal recordó, como relevante para valorar las declaraciones de Perinçek, su jurisprudencia sobre la negación del holocausto, incluidas las declaraciones que niegan la existencia de cámaras de gas o que describen el holocausto como una farsa o un mito. Sin embargo, la Corte enfatizó que su evaluación de la necesidad de interferir con las declaraciones relacionadas con eventos históricos ha sido «bastante específica para cada caso y ha dependido de la interacción entre la naturaleza y los efectos

$23 \$ 124$.

$24 \$ 131$.

$25 \$ 140$.

26 De entre la abundante bibliografía, citamos sólo la obra que nos parece la mejor síntesis en lengua castellana: GARCía RoCA, J. (20 I O). El margen de apreciación nacional en la interpretación del Convenio Europeo de Derechos Humanos: soberanía e integración, Civitas-Thomson Reuters, Madrid.

27 Solicitudes n. 4149/04 y 41029/04 (2012).

(C) UNED. Revista de Derecho Politico

N. ${ }^{\circ} 109$, septiembre-diciembre 2020, págs. 345-370 
potenciales de tales declaraciones y el contexto en el que se hicieron». En consecuencia, el Tribunal evaluó la negativa pública de Perinçek del genocidio armenio a través de los siguientes factores: (1) la naturaleza de sus declaraciones; (2) los factores geográficos e históricos; (3) el tiempo en que se hicieron; (4) la medida en que los derechos de los armenios se vieron afectados a consecuencia de las declaraciones; (5) la existencia o falta de consenso entre los Estados partes sobre la tipificación como delito de la negación del genocidio, y (6) la gravedad de la interferencia.

(1) La naturaleza de las afirmaciones de Perinçek

En la jurisprudencia del TEDH, la libertad de expresión sobre asuntos de interés público tiene, en principio, derecho a una protección sólida, mientras que la expresión que promueve o justifica la violencia, el odio, la xenofobia u otra forma de intolerancia no puede reclamar protección ${ }^{28}$. El Tribunal sostuvo que las declaraciones de Perinçek se referían a un asunto de interés público porque expresó sus puntos de vista como político, más que como un erudito historiador. Además, sostuvo que las declaraciones no equivalían a incitación a la violencia o al odio con el argumento de que Perinçek no expresó desprecio ni odio por las víctimas de los acontecimientos de 1915 ni llamó mentirosos a los armenios ni intentó estereotiparlos ${ }^{29}$.

El Tribunal concluyó que sus comentarios «eran virulentos y que su posición era intransigente, pero debería reconocerse que aparentemente incluían un elemento de exageración al tratar de atraer la atención ${ }^{30}$.

(2) Factores geográficos e históricos

El Tribunal reconoce que la negación del holocausto puede ser particularmente peligrosa en países que han experimentado los horrores del nacismo y que, precisamente por eso, tienen una especial responsabilidad moral para prohibir tal negación. En este caso, el TEDH no encontró un «vínculo directo entre Suiza y los eventos que tuvieron lugar en el Imperio Otomano en 1915 y los años siguientes $»^{31}$. En particular, sostuvo que es difícil afirmar que "cualquier hostilidad que exista hacia la minoría armenia en Turquía es producto de [sus] declaraciones en Suiza o que [su] condena penal en Suiza protegió de algún modo real los derechos de esa minoría o la hizo sentirse más segura» ${ }^{32}$.

(3) Factor temporal

El Tribunal también consideró el lapso de tiempo transcurrido entre las declaraciones de Perinçek y los eventos de 1915, sosteniendo lo siguiente: «Mientras que los eventos de época relativamente reciente pueden ser tan traumáticos como para garan-
$\S 229$.
$\S 233$.
$\S 239$.
$\S 244$.
$\S 246$. 
tizar, por un período de tiempo, un mayor grado de regulación de las declaraciones relacionadas con ellos, la necesidad de tal regulación está destinada a retroceder con el paso del tiempo» ${ }^{33}$.

(4) Hasta qué punto las declaraciones afectaron los derechos de los armenios

El Tribunal reconoció la «inmensa importancia» atribuida a los acontecimientos de 1915 y los años siguientes, pero no aceptó que las declaraciones de Perinçek «fueran tan perjudiciales para la dignidad de los armenios que sufrieron y perecieron en estos eventos y para la dignidad e identidad de sus descendientes como para exigir medidas de Derecho penal en Suiza» ${ }^{34}$. Razonó, entre otras cosas, que sus declaraciones no estaban dirigidas a la comunidad armenia sino a los «imperialistas», a quienes consideraba responsables de las atrocidades ${ }^{35}$.

(5) Existencia o ausencia de consenso entre los Estados parte del Convenio.

El Tribunal analiza si otros Estados parte del Convenio han tipificado como delito la negación de hechos históricos, constatando que Austria, Bélgica, Francia, Alemania, Holanda y Rumanía han tipificado como delito solo la negación del holocausto judío y los crímenes del nacismo mientras que Andorra, Chipre, Hungría, Letonia, Lichtenstein, Lituania, Luxemburgo, la Antigua república yugoslava de Macedonia, Malta, Eslovaquia, Eslovenia, y Suiza, tipifican como delito la negación de cualquier genocidio. A pesar de ello, el Tribunal considera que Suiza «se encuentra en un extremo del espectro comparativo», ya que penaliza la negación de cualquier genocidio sin «el requisito de que se lleve a cabo de una manera que pueda incitar a la violencia o al odio» ${ }^{36}$.

(6) Gravedad de la interferencia

Por último, el Tribunal sostuvo que la condena penal de Perinçek, que podría concluir con el encarcelamiento del acusado, estaba sujeta a un escrutinio estricto y, por lo tanto, era severa, particularmente, cuando el Gobierno suizo podía imponer otro tipo de sanciones. La Gran Sala hizo una evaluación detallada de todos los aspectos relevantes del caso y finalmente concluyó que «las declaraciones del solicitante se referían a un asunto de interés público y no equivalían a un llamamiento al odio o la intolerancia» ${ }^{37}$, que el contexto en el que se hicieron no estuvo marcado por tensiones

33 «Whereas events of relatively recent vintage may be so traumatic as to warrant, for a period of time, an enhanced degree of regulation of statements relating to them, the need for such regulation is bound to recede with the passage of time.» $\S 250$.

$34 \$ 252$

$35 \S 252$.

36 Switzerland «stands at one end of the comparative spectrum» as it criminalizes the denial of any genocide without «the requirement that it be carried out in a manner likely to incite to violence or hatred.» $\$ 257$.

37 El demandante (Perinçek) tampoco había expresado desprecio hacia las víctimas de los hechos, cfr.: BouazZa Ariño, O., op. cit., p. 257.

(C) UNED. Revista de Derecho Politico

N. ${ }^{\circ} 109$, septiembre-diciembre 2020, págs. 345-370 
intensas o connotaciones históricas especiales en Suiza, que no se puede considerar que las declaraciones afecten la dignidad de los miembros de la comunidad armenia hasta el punto de exigir una respuesta de Derecho penal en Suiza, que no existe una obligación de Derecho internacional que obligue a Suiza a penalizar tales declaraciones, que los tribunales suizos parecen haber censurado al solicitante por expresar una opinión que difería de la opinión mayoritaria en Suiza.

Teniendo en cuenta todos los factores mencionados anteriormente, el Tribunal concluyó que la interferencia del Gobierno suizo con el derecho de Perinçek a la libertad de expresión no era necesaria en una sociedad democrática y, por tanto, había lesionado el art. 10 de la Convención. Finalmente, el Tribunal decidió, por trece votos contra cuatro, que no se encontraban motivos para aplicar el artículo 17 del CEDH.

\subsubsection{Consideraciones finales}

Estimamos que los fundamentos de esta sentencia constituyen un ejemplo paradigmático de las circunstancias que rodean a las declaraciones de un político. Además de los elementos clásicos para realizar el juicio de proporcionalidad, se introduce aquí el análisis de la naturaleza de las declaraciones, del contexto geográfico e histórico, del factor temporal, del efecto real en los derechos de otros, del consenso entre los Estados y de la gravedad de la interferencia. El análisis de estos seis factores llevó al TEDH a pronunciarse a favor del Sr. Perinçek. El Tribunal de Estrasburgo rechazó por unanimidad la aplicación el abuso de derecho $(\operatorname{art} .17 \mathrm{CEDH})^{38}$. Asimismo, fue decisiva la valoración que el TEDH hace de la intencionalidad del condenado. Refiriéndose al Sr. Perinçek, estimó que no había «elementos para probar en este caso una intención racista y antidemocrática, tampoco genocida» ${ }^{39}$. El TEDH hace suya la afirmación del TC español en el caso Varela Geiss: «La justificación de un genocidio no consiste en afirmar que un evento particular no constituye genocidio, sino en formular conductas expresivas haciendo un juicio de valor sobre un genocidio relativizando la gravedad o poniéndola en cuestión» ${ }^{40}$.

38 Sobre esto, puede verse Hong, M. (2010). «Hassrede und extremistische Meinungsäußerungen in der Rechtsprechung des EGMR und nach dem Wunsiedel-Beschluss des BVerfG», en: Zeitschrift für ausländisches öffentliches Recht und Völkerrecht, n. 70, pp. 107-108.

39 Elósegui Itxaso, M. (2017). «La negación o justificación del genocidio como delito en el Derecho Europeo. Una propuesta a la luz de la Recomendación n. 15 de la ECRI», en: Revista de Derecho Político, n. 98, enero-abril p. 321.

${ }^{40} \S 240$ de la sentencia en el caso Perinçek. Sobre esto, véase: ElósEgui ItXaso, M., op. cit., p. 322. 


\section{CRITERIOS INTERPRETATIVOS DE LOS LÍMITES A LA LIBERTAD DE EXPRESIÓN DE LOS POLÍTICOS}

Trataremos en este apartado de extraer, en la medida en que ello resulte posible, algunas consideraciones generales acerca de los límites a la libertad de expresión de los políticos, a tenor de la jurisprudencia de Estrasburgo.

\subsection{Libertad de expresión de la clase política}

Por lo que se refiere a su consideración como representantes de sus electores, la libertad de expresión resultaría más amplia ${ }^{41}$ si proviene de la clase política ${ }^{42}$. Pero esa amplia libertad de expresión ${ }^{43}$, como una de las precondiciones de funcionamiento de la democracia ${ }^{44}$, no excluye el deber de respeto específico a la ley, incluida la que prohíbe toda discriminación, como prevé el Código de conducta de los Parlamentarios británicos ${ }^{45}$. De hecho, cuando el TEDH ha impuesto restricciones a la libertad de expresión de los políticos, lo ha hecho precisamente porque causaban algún tipo de discriminación: a los extranjeros en el caso Féret c. Bélgica; a los musulmanes, en el caso Norwood c. Reino Unido ${ }^{46}$. Ciertamente, los políticos tienen también prohibido

41 «El artículo 10. 2 del CEDH apenas deja lugar a restricciones a la libertad de expresión en el ámbito del discurso político y el especial valor que esa libertad tiene, para un «electo por el pueblo, que representa a sus electores» SERRANO Maíllo, I. (2011). «El derecho a la libertad de expresión en la jurisprudencia del tribunal europeo de derechos humanos: dos casos españoles», en: Teoría y Realidad Constitucional, vol. 28, p. 594.

42 Martín Herrera, D. (2014). «Libertad de expresión: ¿Derecho ilimitado según el Tribunal Europeo de Derechos Humanos? Del Discurso de odio al crimen de odio», en: Cuadernos de Deusto, vol. 62 , n. 2, , en torno a la nota 40. Accesible en http://revista-estudios.revistas.deusto.es/article/ view/249/395 [último acceso 25-04-2020].

43 Serrano Maíllo, I., op. cit., pp. 591 y ss., sostiene que libertad de expresión es especialmente valiosa en manos de esos sujetos, dado que han sido elegidos por el pueblo.

44 Presno Linera, M. Á. (2020). «La libertad de expresión según el Tribunal Europeo de Derechos Humanos», en: Revista de la Facultad de Derecho de México, vol. 70, n. 276, Enero-Abril, pp. 464, citando el asunto Appleby y otros c. Reino Unido, de 6 de mayo de 2003.

45 Bustos Gisbert, R. (2016). «Las reglas de conducta de los políticos. Evolución en Reino Unido», en: Revista Vasca de Administración Pública, núm. 104-II. Enero-Abril p. 284, cita del Código de Conducta de los Parlamentarios Ingleses.

46 Sentencia n. 23131/03, de 16 Noviembrede 2004. Hong, M., op. cit., p. 100, comenta que, a pesar de que el TEDH considera los carteles de las torres gemelas ardiendo con la leyenda de defender a Gran Bretaña del Islam, entra dentro del radio de acción del art. 17, esta decisión habría requerido, según el Derecho alemán, una ponderación más detallada de los bienes en conflicto. Según el Derecho alemán, habría que haber considerado que las expresiones dirigidas a manifestar una posición contraria a los extranjeros, ciertamente son contrarias a la tolerancia que debe esperarse en un orden democrático libre; sin embargo, en el Código Penal alemán no están tipiticadas como delito.

(C) UNED. Revista de Derecho Politico

N. ${ }^{\circ} 109$, septiembre-diciembre 2020, págs. 345-370 
el discurso que incita al odio o la violencia, pero esta limitación es general, no les atañe sólo a ellos ${ }^{47}$.

Está por desarrollar en la Jurisprudencia de Estrasburgo cómo puede compaginarse la licitud de los programas políticos que contienen previsiones de hecho discriminatorias, y la prohibición a sus líderes, incluso cuando ya son parlamentarios electos, de efectuar declaraciones o hacer propaganda de ideas que se corresponden con el programa político. Habría que armonizar la jurisprudencia relativa a la prohibición de partidos políticos con la relativa a los límites a la libertad de expresión de los políticos. Habría que garantizar que los políticos pueden ejercitar su derecho a la libertad de expresión, dentro de un contexto electoral, en la medida en que sus declaraciones se correspondan con su programa político. La pretensión de limitar las expresiones de los candidatos a un margen más reducido que el de su programa electoral, debería incluir la obligación de interponer simultáneamente un recurso contra el propio programa político del partido.

\subsection{Criterios interpretativos de algunos conceptos jurídicos indeterminados de Derecho convencional: orden público (1), necesidad en una sociedad democrática (2) e interés público (3)}

(1) El TEDH en sus decisiones relativas a la libertad de expresión de los políticos no ha hecho uso en ninguna de ellas de un concepto de «orden público» específico para los representantes de los electores. Por el contrario, sí ha elaborado un concepto de orden público específico para los miembros de las Fuerzas Armadas ${ }^{48}$, como límite a su libertad de expresión. En el caso de la delimitación del concepto de orden público aplicado a los miembros de los cuerpos y fuerzas de seguridad del Estado, la justificación podría resumirse así: la garantía del orden público no se refiere solo a los lugares públicos (plazas, calles) sino también al orden dentro de determinados grupos sociales, especialmente de aquellos que tienen una función específica dentro del Esta-

47 Entre la abundante bibliografía sobre discurso del odio, puede verse, Teruel Lozano, G. M. (20I7). «El discurso del odio como límite a la libertad de expresión en el marco del Convenio Europeo de Derechos Humanos», en: Revista Española de Derecho Constitucional Europeo, n. 27, Enero-Junio, https:// www.ugr.es/ redce/REDCE27/articulos/03_TERUEL.htm [último acceso 25-04-2020]. VALERO Heredia, ANa (2017), «Los discursos del odio. Un estudio jurisprudencial», en: Revista Española de Derecho Constitucional, n. 110, pp. 305-333. Soto García, M. (2012) «TEDH - Sentencia de 15.03.2011, Otegui Mondragón c. España, 2034/07 - Artículo 10 del CEDH - Libertad de Expresión - Límites - Delito de Injurias contra el Jefe del Estado - Exhortación a la Violencia y Discurso de Odio», en: Revista de Derecho Comunitario Europeo, vol. 42, Madrid, pp. 575-591. Presno Linera, M. Á. (2018). «Crónica de una condena anunciada: El asunto Stern Taulats y Roura Capellera c. España sobre la quema de fotos del Rey», en: Teoría y Realidad Constitucional, n. 42, pp. 539-549

48 Grote, R.; Winzel, N. (2013). «Die Meinungsfreheit», en: Dörr, O.; Grote R.; Marauhn T., (hrsg.), Konkordanzkommentar zum europäischen und deutschen Grundrechtsschutz, 2. Auflage, Bd.I, Mohr Siebeck, Tübigen, p. 1115, véase la jurisprudencia citada en la nota 399. 
do, y con respecto a los cuales, una lesión de su orden interno podría acarrear consecuencias para la entera sociedad ${ }^{49}$.

A mi modo de ver, es correcto que no se haya elaborado un concepto de «orden público» específico para los representantes políticos. Si lo hubiera, tal vez se reforzaría aún más la posición de los partidos políticos; no parece oportuno ese reforzamiento.

(2) En cambio, en esta jurisprudencia (sobre todo a partir del caso Perinçek), se ha declarado de modo inequívoco para supuestos futuros que la «necesidad en una sociedad democrática» es un concepto autónomo de Derecho convencional, cuyo contenido no puede determinarse según el criterio del Derecho nacional ${ }^{50}$. A mi parecer, este aserto tiene un alcance cuyas consecuencias no se pueden prever en toda su extensión, pues supone dejar una llave en manos del TEDH para que entre a valorar los hechos de modo distinto a como eventualmente lo haya hecho la jurisdicción nacional. Además, de la dificultad que entraña la distinción entre «hechos probados» y «juicios de valor», ya existente en cualquier caso.

Ello, además, despeja toda duda acerca de si lo que se protege es el orden constitucional o el orden democrático ${ }^{51}$ : está claro que lo que se protege es este último.

(3) Asimismo, como criterio interpretativo del concepto de «interés público», cabe afirmar que, en la media en que la conducta sea «de interés público», la posibilidad de que las autoridades nacionales la limiten es menor ${ }^{52}$.

\subsection{Aplicación restrictiva del art. 17 del CEDH}

Como es sabido, el art. 17 del CEDH prohíbe el abuso de derecho («ninguna de las disposiciones del presente convenio podrá ser interpretada en el sentido de implicar para un Estado, grupo o individuo, un derecho cualquiera a dedicarse a una actividad o a realizar un acto tendente a la destrucción de los derechos o libertades reconocidos en el presente Convenio o a limitaciones más amplias de estos derechos o libertades que las previstas en el mismo» $)^{53}$.

49 Grote, R.; Winzel, N., op. cit., p. 1115.

50 Grote, R.; Winzel, N., op. cit., p. 1114 y p. 1119, citando la jurisprudencia del TEDH.

51 Con carácter general, puede verse: CATALÀ I BAS, A. H. (2001). «Valores y principios democráticos como límite a la libertad de expresión», en: Cuadernos de Derecho Público, n. 14, septiembrediciembre, pp. 131-187. Específicamente sobre el abuso de derecho y la defensa de la democracia, García Roca, J. (2014). «Abuso de los derechos fundamentales y defensa de la democracia (art. 17 CEDH) », en: García Roca, J.; SAntolaya, P., (coords.) La Europa de los derechos: El Convenio Europeo de Derechos Humanos, $3^{\text {a }}$ ed., CEPC, Madrid, especialmente pp. 638-639.

52 Elósegui Itxaso, M., op. cit, p. 322, aplicada al Gobierno suizo en el caso Perinçek.

53 Arai, Y. (2006). «Prohibition of Abuse of the Rights and Freedoms Set Forth in the Convention and of Their Limitation to a Greater Extent Than is Provided for in the Convention (Article 17)», en: VAN DijK P.; VAN Hoof, F.; VAN Rijn A.; ZwaAk, L. (eds.), Theory and practice of the European Convention on Human Rights, 4. Ed. Antwerpen-Oxford, pp. 1083-1093. Y en la última edición de esta obra: BuYSE, A. (2018). «Prohibition of Abuse of the Rights and Freedoms Set Forth in the Convention and of Their Limitation to a Greater Extent Than is Provided for in the Convention (Article 17)», en: VAN DijK P.; 
La jurisprudencia muestra que, cuando se trata de la negación o revisión de temas controvertidos de debate histórico, el enfoque de Estrasburgo acerca de la aplicación del art. $17 \mathrm{CEDH}$ no ha sido uniforme ${ }^{54}$. De hecho, la juez Nussberger, en su voto particular a la sentencia del caso Perinçek, criticó la discrepancia entre el enfoque de Estrasburgo para la aplicación del artículo 17 del TEDH en el caso de la negación del Holocausto, por un lado, y la negación de otros genocidios, crímenes de guerra y crímenes contra la humanidad, por otro. En su opinión disidente se cuestionaba « ¿por qué las sanciones penales por la negación de la caracterización de las masacres de armenios en Turquía en 1915 como 'genocidio'constituyen una violación de la libertad de expresión, mientras que las sanciones penales por la negación del Holocausto se han considerado compatibles con la Convención?» A pesar de que la sensibilidad de la Corte cuando se enfrenta a cuestiones relacionadas con los horrores de la Segunda Guerra Mundial puede explicarse considerando el contexto en el que se acordó el Convenio. Se argumenta acertadamente que «no es fácil defender por qué la línea debe trazarse allí». Sin embargo, hay un aspecto en el que la Jurisprudencia del TEDH es uniforme: Cuando se trata de hechos históricos claramente establecidos, como es el caso del Holocausto Judío, su negación queda sustraída del ámbito de protección del art. 10 del CEDH, en aplicación del art. 17 del $\mathrm{CEDH}^{55}$. Quizá el TEDH sigue el criterio de que «la aplicación de la teoría del abuso de derecho debe tener un carácter subsidiario en defecto de reglas más nítidas » ${ }^{56}$, como ha señalado García Roca.

Sin embargo, en otros casos el TEDH sí ha aplicado el art. 17, en relación con los límites a la libertad de expresión de los políticos. En el caso Nordwood, estimó que «no puede ampararse en la libertad de expresión (en aplicación del art. 17) la difusión de un cartel que contenía una foto de las torres gemelas en llamas, junto al eslogan 'Islam fuera de Gran Bretaña. Proteged al pueblo británico' y la imagen típica de la

VAN HoOf, F.; VAN Rijn A.; ZwaAK, L., (eds.), Theory and practice of the European Convention on Human Rights, $5^{\text {th }}$. Ed. pp. 1083-1093. Schabas, W. A. (2015).The European Convention on Human Rights: A Commentary, Oxford Commentaries on International Law, pp. 1965 y ss.

54 Alcárcer Guirao, R. (2013). «Libertad de expresión, negación del holocausto y defensa de la democracia. Incongruencias valorativas en la jurisprudencia del TEDH», en: Revista de Derecho Constitucional, n. 97, p. 315, recoge el criterio de la jurisprudencia de Estrasburgo, que con carácter general ha declarado que «cualquier manifestación contra los valores plasmados en la Convención se vería excluida de la protección del artículo 10 a través del artículo 17». Gascón CuenCA, A. (2018). «La negación de los delitos de genocidio en la jurisprudencia del Tribunal Europeo de Derechos Humanos a partir de la sentencia Perinçek contra Suiza», en: Anuario de filosofía del derecho, vol. 34, p. 183-184, «el TEDH en su jurisprudencia ha decidido que la negación, la trivialización o la justificación de los hechos ocurridos durante el III Reich en Alemania supone un abuso de derecho del artículo 10 $\mathrm{CEDH}$, en combinación con el artículo $17 \mathrm{CEDH}$. Así mismo, la doctrina del TEDH considera como un abuso de derecho la protección bajo la libertad de expresión de ideologías totalitarias contrarias a la

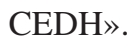

55 Lazcano Brotóns, I. (2015) «Prohibición del abuso de derecho», en: Lasagabaster Herrarte, I., (dir.), Convenio Europeo de Derechos Humanos. Comentario sistemático, $3^{a}$ ed., Cizur Menor (Navarra), p. 834.

56 García Roca, J., «Abuso de los derechos fundamentales..., loc. cit, nota 49, p. 637. 
luna creciente y la estrella dentro de una señal de prohibición. El cartel se considera un ataque para todos los musulmanes del Reino Unido» ${ }^{57}$. Este ataque contra un grupo religioso, vinculándolo con un grave acto terrorista, se considera incompatible con los valores protegidos por el Convenio, por ello se inadmitió del recurso del demandante (dirigente regional de un partido de extrema derecha). La posición del TEDH en esta decisión, ha llevado a Lazcano a criticar que «la utilización del art. 17, en este caso, no parece coherente con otros asuntos similares en materia de libertad de expresión en los que el TEDH entra a valorar la necesidad de la restricción impuesta desde el parámetro del art. 10,2 del $\mathrm{CEDH}{ }^{58}$.

La jurisprudencia vacilante en torno al art. 17 del CEDH, pone de manifiesto que si bien es cierto que «no puede negarse la realidad del abuso como fenómeno jurídico. La cuestión es si ese dato es suficiente para crear una norma de principios, bastante imprecisa, que permita resolverlos, dados los riesgos que entraña una acción valorativa tan libre por parte del juzgador ${ }^{59}$. No en vano, como señala García Roca, refiriéndose al art. 17, «si el efecto útil de este artículo autoriza a los Estados a someter a los liberticidas a limitaciones especiales más gravosas, paradójicamente, se estaría vaciando de contenido la interdicción de introducir tácitamente restricciones mayores que las previstas» ${ }^{60}$.

La jurisprudencia de Estrasburgo, mantiene que los límites de los derechos no pueden aplicarse como cláusulas con carácter preventivo frente a eventuales riesgos. Para que prevalezca el límite sobre el libre ejercicio de un derecho, deben quedar debidamente acreditados los elementos de riesgo y que la medida adoptada sea proporcionada y adecuada a los fines perseguidos. En el caso del ejercicio del derecho a la libertad de expresión por parte de los representantes políticos, los límites a su libertad de expresión son los valores democráticos ${ }^{61}$, quizá se justifique la distinta decisión en el caso de Féret c. Bélgica, porque mediante su discurso se perjudicaba a los derechos de los extranjeros; en cambio, en el caso de la negación del genocidio armenio por parte de un político turco en Suiza, no quedó demostrado que sus declaraciones produjeran un perjuicio a los derechos de los armenios.

En la teoría general del Derecho ${ }^{62}$, se designa al abuso de derecho como el ejercicio de un derecho propio sin contravenir los límites de la legalidad, pero con el fin de perjudicar a otro; por ello, resulta ser un ejercicio antijurídico de un derecho realizado por su titular. También se ha definido como el ejercicio de un derecho contra

57 Lazcano Brotóns, I., op. cit., pp. 834-835.

58 Ibid. pp. 834-835.

59 García Roca, J., «Abuso de los derechos fundamentales..., loc. cit, nota 49, p. 637.

60 García Roca, J., «Abuso de los derechos fundamentales..., loc. cit, nota 49, p. 632.

61 CATALÀ I BAS, A. H. (200I), Libertad de expresión e información. La jurisprudencia del TEDH y su recepción por el Tribunal Constitucional: hacia un derecho europeo de los derechos humanos, Ediciones Revista General de Derecho, Valencia, pp. 337 y ss.

62 Carrasco Perera, Á. (2016) Tratado del abuso de derecho y del fraude de ley, ed. Civitas-Thomson Reuters, Cizur Menor. Rodovalho, T. (2011), Abuso de Derecho y derechos subjetivos, ed. Olejnik, Santiago de Chile.

(C) UNED. Revista de Derecho Político

N. ${ }^{\circ} 109$, septiembre-diciembre 2020, págs. 345-370 
su razón de ser y en perjuicio de tercero. En Derecho privado, donde este concepto tiene su origen, se atribuye al abuso de derecho un significado objetivo y otro subjetivo que pueden ser concurrentes o complementarios. El elemento subjetivo consiste en la intención de dañar, en ausencia de otra finalidad legítima. El elemento objetivo es el ejercicio del derecho de modo anormal, es decir, contrario a sus fines económico-sociales ${ }^{63}$.

En mi opinión, la dificultad para aplicar estas categorías a la teoría general de los derechos fundamentales radica en el fuerte contenido subjetivo que la jurisprudencia del TEDH atribuye a estos derechos. Si el ejercicio de un derecho fundamental (en el objeto de este trabajo, la libertad de expresión), no contraviene los límites de la legalidad, aunque su titular (en este caso, un representante político) pueda tener el fin de perjudicar a otro (por ejemplo, su adversario político), resultará difícil aplicar la doctrina del abuso de derecho para limitar su ejercicio. Debido a la importancia que el derecho a la libertad de expresión tiene para la democracia, también resultará difícil probar que se ejerce sólo con intención de dañar y sin otra finalidad legítima. Sin embargo, esta puede ser la vía por la que se aplique la cláusula del abuso de derecho: demostrando el daño. En mi opinión, la búsqueda de algunos elementos objetivos en la ponderación de los límites del derecho a la libertad de expresión de los políticos (como de otros derechos del CEDH), parece necesaria. Si el contenido del derecho queda por entero a la libre interpretación de su propio titular, entonces no ya instituciones como el abuso de derecho sino la existencia misma de una instancia juzgadora externa y con jurisdicción sobre las partes, terminaría debilitándose.

\section{CONSIDERACIONES CONCLUSIVAS}

Las dos sentencias del TEDH que hemos tratado de comparar ponen de manifiesto la dificultad de construir criterios generales en la interpretación de la libertad de expresión de los representantes políticos. En la medida en que esos límites sean previsibles, se facilitará que no haya limitaciones injustificadas ni arbitrarias del derecho a la libertad de expresión. Pero, a la vez, la elaboración de criterios generales demasiado abstractos, puede que no garantice que se impida el ejercicio abusivo e ilícito de tal derecho. Buena prueba de ello es que las dos sentencias cuentan con opiniones disidentes que aportan, al igual que los fundamentos jurídicos de las sentencias, sólidos argumentos.

A mi parecer, aún no hay suficiente jurisprudencia como para elaborar una construcción dogmática sólida sobre el abuso de derecho en el ejercicio de la libertad de

63 Entre las principales sentencias del TS sobre el abuso de derecho, cabe destacar, la STS de 14 de febrero de 1986 que señaló que en lugar de «abuso de derecho» debería hablarse de abuso en el ejercicio del derecho». La STS de 28 de enero de 2008 lo califica como un concepto jurídico indeterminado cuya esencia consiste en sobrepasar manifiestamente los límites normales del ejercicio de un derecho (vid. también SSTS de 14 de diciembre de 2007 y 4 de junio de 2009). 
expresión. Asimismo, conviene ser conscientes tanto de las ventajas como de los riesgos que entrañan los conceptos jurídicos convencionales que ya cuentan con una interpretación estable.

\section{REFERENCIAS BIBLIOGRÁFICAS}

Alcárcer Guirao, Rafael, «Libertad de expresión, negación del holocausto y defensa de la democracia. Incongruencias valorativas en la jurisprudencia del TEDH», Revista de Derecho Constitucional, n. 97, 2013, pp. 309-341.

Arai, Yutaka, «Prohibition of Abuse of the Rights and Freedoms Set Forth in the Convention and of Their Limitation to a Greater Extent Than is Provided for in the Convention (Article 17)», en: Theory and practice of the European Convention on Human Rights, Pieter van Dijk /Fried van Hoof/ Arjen van Rijn Leo ZwAAK, (eds.) 4. Ed. Antwerpen-Oxford, 2006, pp. 1083-1093.

Bustos Gisbert, Rafael, «Los derechos de libre comunicación en una sociedad democrática», en: La Europa de los derechos: El Convenio Europeo de Derechos Humanos, García Roca, Javier / Santolaya, Pablo (coords.), 3a ed., CEPC, Madrid, 2014, pp. 473-509.

Buyse, Antoine, «Prohibition of Abuse of the Rights and Freedoms Set Forth in the Convention and of Their Limitation to a Greater Extent Than is Provided for in the Convention (Article 17)», en: Theory and practice of the European Convention on Human Rights, Pieter van Dijk /Fried van Hoof/ ArJen van Rijn LEO ZWAaK, (eds.), $5^{\text {th }}$. Ed. 2018, pp. 1083-1093.

Carrasco Perera, Ángel, Tratado del abuso de derecho y del fraude de ley, ed. Civitas-Thomson Reuters, Cizur Menor, 2016.

Català i Bas, Alexandre H., "¿Tolerancia frente a la intolerancia? El respeto a los valores y principios democráticos como límite a la libertad de expresión», en: Cuadernos de Derecho Público, n. 14 (septiembre-diciembre 2001), pp. 131-187.

Català i Bas, Alexandre H., Libertad de expresión e información. La jurisprudencia del TEDH y su recepción por el Tribunal Constitucional: hacia un derecho europeo de los derechos humanos, Ediciones Revista General de Derecho, Valencia, 2001.

Combalía Solís, Zoila, «Libertad de expresión y religión en Estados Unidos y en Europa: dos modos de entender la democracia», en www.iustel.com Revista General de Derecho Canónico y Derecho Eclesiástico del Estado, n. 45, 2017.

Elósegui Itxaso, María, «La negación o justificación del genocidio como delito en el Derecho europeo. Una propuesta a la luz de la Recomendación n. 15 de la ECRI», en: Revista de Derecho Político 1(98): 2017 251. DOI: 10.5944/ rdp.98.2017.18657

GARCÍA RoCA, JAVIER, El margen de apreciación nacional en la interpretación del Convenio Europeo de Derechos Humanos: soberanía e integración, Civitas-Thomson Reuters, Madrid, 2010.

(C) UNED. Revista de Derecho Politico

N. ${ }^{\circ} 109$, septiembre-diciembre 2020, págs. 345-370 
García Roca, Javier, «Abuso de los derechos fundamentales y defensa de la democracia», en: García Roca, Javier / Santolaya, Pablo (coords.) La Europa de los derechos: El Convenio Europeo de Derechos Humanos, $3^{\mathrm{a}}$ ed., CEPC, Madrid, 2014, pp. 631-656.

Gascón Cuenca, Andrés, «La negación de los delitos de genocidio en la jurisprudencia del Tribunal Europeo de Derechos Humanos a partir de la sentencia Perinçek contra Suiza», en: Anuario de filosofía del derecho, vol. 34, 2018, pp. 177-197.

Grote, Reiner / Winzel, Nicola, «Die Meinungsfreheit», en: Oliver Dörr / Rainer Grote / Thilo Marauhn, (hrsg.), Konkordanzkommentar zum europäischen und deutschen Grundrechtsschutz, 2. Auflage, Bd.I, Mohr Siebeck, Tübigen, 2013, pp. 1050-1160.

Hong, Mathias, «Hassrede und extremistische Meinungsäußerungen in der Rechtsprechung des EGMR und nach dem Wunsiedel-Beschluss des BVerfG», en: Zeitschrift für ausländisches öffentliches Recht und Völkerrecht, n. 70, 2010, pp. 73-126.

Lasagabaster Herrarte, IÑigo, «Restricciones a la actividad política de los extranjeros», en: Lasagabaster Herrarte, IÑigo, (dir.), Convenio Europeo de Derechos Humanos. Comentario sistemático, $3^{\mathrm{a}}$ ed., Cizur Menor (Navarra), 2015, pp. 819-823.

LAzCANO Brotóns, IÑIgo, «Libertad de expresión», en: LASAGabaster HerRaRTE, IÑIgo, (dir.), Convenio Europeo de Derechos Humanos. Comentario sistemático, $3^{\text {a }}$ ed., Cizur Menor (Navarra), 2015, pp. 510-630.

— «Prohibición del abuso de derecho», en: Lasagabaster Herrarte, IÑigo, (dir.), Convenio Europeo de Derechos Humanos. Comentario sistemático, $3^{\mathrm{a}}$ ed., Cizur Menor (Navarra), 2015, pp. 825-842.

Martín Herrera, David, «Libertad de expresión: ¿Derecho ilimitado según el Tribunal Europeo de Derechos Humanos? Del Discurso de odio al crimen de odio», en: Cuadernos de Deusto, vol. 62, n. 2, 2014, accesible en http://revista-estudios.revistas.deusto.es/article/view/249/395

Pariente de la Prada, José Ignacio, «Un Nuevo concepto de ciudadanía europea: Comentario a la Sentencia del Tribunal Europeo de Derechos Huamnos de 27 de abril de 1995 en el Asunto Piermont c. Francia», en: Revista Vasca de Administración Pública, 1996, 44 (I), pp. 231-250.

Presno Linera, Miguel Ángel, «Crónica de una condena anunciada: El asunto Stern Taulats y Roura Capellera c. España sobre la quema de fotos del Rey», en: Teoría y Realidad Constitucional, n. 42, 2018, pp. 539-549.

- «La libertad de expresión según el Tribunal Europeo de Derechos Humanos», en: Revista de la Facultad de Derecho de México, vol. 70, n. 276, Enero-Abril 2020, pp. 462-491.

Rodovalho, Thiago, Abuso de Derecho y derechos subjetivos, ed. Olejnik, Santiago de Chile, 2011. 
Schabas, William A., The European Convention on Human Rights: A Commentary, Oxford Commentaries on International Law, 2015.

SERrano MaÍllo, IsABEL, «El derecho a la libertad de expresión en la jurisprudencia del tribunal europeo de derechos humanos: dos casos españoles», en: Teoría y Realidad Constitucional, n. 28, 2011, pp. 579-596.

Soto García, Mercedes, «TEDH - Sentencia de 15.03.2011, Otegui Mondragón c. España, 2034/07 - Artículo 10 del CEDH - Libertad de Expresión - Límites - Delito de Injurias contra el Jefe del Estado - Exhortación a la Violencia y Discurso de Odio», en: Revista de Derecho Comunitario Europeo, Vol. 42, Madrid, 2012, pp. 575-591.

Teruel Lozano, Germán M., «El discurso del odio como límite a la libertad de expresión en el marco del Convenio Europeo de Derechos Humanos», en: Revista Española de Derecho Constitucional Europeo, n. 27, Enero-Junio 2017, accesible en https://www.ugr.es/ redce/REDCE27/articulos/03_TERUEL.htm

Tuncel, Turgut Kerem, A look at the Perinçek v. Switzerland case: examination of a lawsuit to understand the current state of the Armenian-Turkish dispute and prospective developments, en: Review of Armenian Studies, n. 31, 2015, pp. 293-324. Accesible en Academia.edu/31442451/A_LOOK_AT_THE_PERİNÇEK_V._SWITZERLAND_CASE_EXAMINATION_OF_A_LAWSUIT_TO_UNDERSTAND_ THE_CURRENT_STATE_OF_THE_ARMENIAN-TURKISH_DISPUTE_AND_PROSPECTIVE_DEVELOPMENTS

Valero Heredia, AnA, «Los discursos del odio. Un estudio jurisprudencial», en: Revista Española de Derecho Constitucional, n. 110, 2017, pp. 305-333.

Title:

Limits To The Freedom Of Expression Of Politicians and Abuse of Rights. The Féret C. Belgium And Perinçek C. Switzerland Cases.

\section{Summary:}

1. Introduction. 2. Summary exposition of both sentences. 2.1. Féret c. Belgium. 2.1.1. Summary of events. 2.1.2. Summary of decision. 2.1.3. Final thoughts. 2.2. Perinçek c. Switzerland. 2.2.1. Summary of events. 2.2.2. Summary of decision. 2.2.3. Final thoughts. 3. Interpretative criteria of the limits to the freedom of expression of politicians. 3.1. Freedom of expression of the political class. 3.2. Interpretative criteria of some indeterminate legal concepts of conventional law. 3.3. Restrictive 
application of art. 17 of the ECHR.. 4. Conclusive considerations.5. Bibliographic references.

\title{
Resumen:
}

Los fundamentos jurídicos y los votos particulares de la primera sentencia ponen de manifiesto que, en la ponderación de los límites a la libertad de expresión de los políticos, se ha de tener en cuenta la circunstancia de que las manifestaciones hayan sido difundidas en campaña electoral así como la relación entre el contenido de las manifestaciones y el programa político de su partido. En el segundo caso analizado, en cambio, las circunstancias que modalizan los límites a la libertad de expresión de un político son valoradas por el daño real de la minoría que se siente lesionada por las declaraciones políticas así como por la gravedad de la sanción impuesta al político. En las dos sentencias que se ha comparado se muestra la dificultad para elaborar criterios generales en la interpretación de los límites a la libertad de expresión de los representantes políticos. La formulación de criterios generales demasiado abstractos, puede que no garantice que se impida el ejercicio abusivo e ilícito de tal derecho. Aún no hay suficiente jurisprudencia como para proponer una construcción dogmática sólida sobre el abuso de derecho en el ejercicio de la libertad de expresión. Asimismo, conviene ser conscientes tanto de las ventajas como de los riesgos que entrañan los conceptos jurídicos convencionales que ya cuentan con una interpretación estable.

\begin{abstract}
:
The legal foundations and the individual votes of the first sentence show that in weighing the limits on the freedom of expression of politicians, the fact that the demonstrations have been broadcast in an electoral campaign must be taken into account and also the relationship between the content of the demonstrations and the political program of his party. In the second case analyzed, the circumstances that shape the limits to the freedom of expression of a politician are valued for the real harm of the minority that feels injured by the political declarations as well as for the seriousness of the sanction imposed on the politician.

The two judgments of the ECHR that we have tried to compare reveal the difficulty of constructing general criteria in the interpretation of the freedom of expression of political representatives. The elaboration of too abstract general criteria, may not guarantee that the abusive and unlawful exercise of this right is prevented. There is not yet enough jurisprudence to elaborate a solid dogmatic construction on the abuse of rights in the exercise of freedom of expression. Likewise, it is convenient to be aware of the advantages and the risks that the conventional legal concepts that already have a stable interpretation entail.
\end{abstract}




\section{Palabras clave:}

libertad de expresión; Convenio Europeo de Derechos Humanos; necesidad en una sociedad democrática; abuso de derecho.

\section{Keywords:}

Freedom of Expression; European Convention of Human Rights; need in a democratic society; abuse of rights. 
